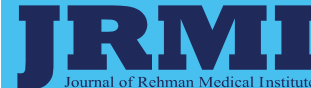

Volume 6, No. 1

January - March 2020

www.jrmi.pk

\section{Submitted}

February 14, 2020

Accepted

March 21, 2020

Author Information

From: Rehman Medical College, Peshawar, Khyber Pakhtunkhwa, Pakistan.

Dr. Bibi Aliya

Assistant Professor

Department of Community

Medicine

(Corresponding Author)

Email: bibi.aliya@rmi.edu.pk

Aymen Imtiaz

Bakhtawar Hasnain

Fourth Year MBBS Students

Dr. Seema Ashraf

Assistant Professor

Department of Community

Medicine

Citation: Aliya B, Imtiaz A, Hasnain B, Ashraf S. KAP study regarding contraceptive use among married women in Hayatabad, Peshawar. J Rehman Med Inst. 2020 JanMar;6(1):3-6.

\title{
KAP study regarding contraceptive use among married women in Hayatabad, Peshawar
}

\author{
Bibi Aliya, Aymen Imtiaz, Bakhtawar Hasnain, Seema Ashraf
}

\section{ABSTRACT}

Introduction: Population growth has great impact on economic development of a country. Despite population growth contraceptive prevalence rate in Pakistan is $35.4 \%$. There is need to increase knowledge and awareness regarding contraception among people of Pakistan.

Objectives: To determine the knowledge, attitude, and practice regarding contraceptive use among married women of Hayatabad, Peshawar, as well as the reasons for not adopting contraception

Materials \& Methods: A cross-sectional descriptive study was conducted in Hayatabad Medical Complex, Peshawar, from March to May 2019 on married women attending the Gynecology Outpatients, who were willing to provide data. Participants were interviewed through a structured questionnaire containing demographics, and relevant sections on Knowledge, Attitude, and Practice of contraceptive use; a section on reasons for not using contraceptives was also included. SPSS version 24.0 and Microsoft Excel were used for descriptive data analysis.

Results: A total of 200 married women were interviewed through structured questionnaires; $76.5 \%$ of them were uneducated. The most prevalent method of contraception was Oral Contraceptive Pills (23\%); $31 \%$ of participants fell below the poverty line with monthly household income of PKR 20,000 or below. Majority (83.2\%) of women showed positive attitude towards contraceptive use.

Conclusion: There is a need to create awareness about the use of contraceptive methods as this awareness is crucial to improve contraceptive prevalence rate of Pakistan.

Keywords: Contraceptive Agents; Contraceptive Prevalence; Family Planning Services.

The authors declared no conflict of interest. All authors contributed substantially to the planning of research, data collection, data analysis, and write-up of the article, and agreed to be accountable for all aspects of the work.

\section{INTRODUCTION}

Family planning is necessary to improve health status of the people. It would be desirable if there is 2-3 years gap between births of each child and if total number of children is limited to 3. By 2050 world population is expected to reach 7 billion. Pakistan has a population of 220 million and contributes to $2.67 \%$ of global population. Pakistan's population was growing at a rate of $2.7 \%$ around 1960. Throughout the 1970s and 1980s the Total Fertility Rate (TFR) was between six and seven births per woman, and the population growth rate approached 3\% per annum. ${ }^{1}$ In 2017 the Total Fertility Rate (TFR) of Pakistan was 2.67 children born per women and the population growth rate was $1.43 \% .^{7}$ The use of contraceptive methods is associated with age of women, their education, source of income, number of their live siblings, age at the time of marriage, child mortality and their knowledge and availability of contraceptives. ${ }^{8}$ Almost $33 \%$ of all currently married women do not want another child immediately or in near future but are not using contraceptive method. ${ }^{9}$ National surveys documented unchanging contraceptive prevalence less than $12 \% .^{2,3}$ Contraceptive prevalence increased from $12 \%$ to $24 \%$ in $1996-97^{4}$ (a rise of roughly 2 percentage points per annum) followed by a reported CPR of $27.6 \% .{ }^{5}$ Pakistan's statistics in 2002 showed contraceptive prevalence of any method as $28 \%$ and of modern methods as $20 \%{ }^{6}$ In 2012-2013, the contraceptive prevalence rate was $35.4 \%$ and in 2017 it increased by $2 \%$ to reach $37.4 \%$. $^{7}$

This study was conducted to assess knowledge attitude and practice of family planning methods among married women of Hayatabad, Peshawar, and to study the reasons for lack of contraceptive use in these women.

\section{MATERIALS \& METHODS}

The current cross-sectional descriptive study was conducted from March to May 2019 in Hayatabad, Peshawar, Khyber Pakhtunkhwa, through convenience sampling. A sample of 200 married women coming to Gynecology Outpatients of Hayatabad Medical Complex was interviewed after taking their consent and using a structured questionnaire. Self-structured questionnaire was 
designed based on objectives taking help from previous literature and studied available on topic added with specific questions. Questionnaire was composed of close-ended questions. The random sampling technique was used for data collection. SPSS and Microsoft Excel were used for organizing the collected data obtained by interviewing the married women.

\section{RESULTS}

A total of 200 women participated in the study, aged 15-67.Out of 200 women only $79(39.5 \%$ ) were using any form of contraception. It was noticed that with the advancement in age use of contraception did not increase and it was statistically insignificant with $\mathrm{p}=0.515$. Among the participants $76 \%$ of people were illiterate and only $23 \%$ have had education above primary school.

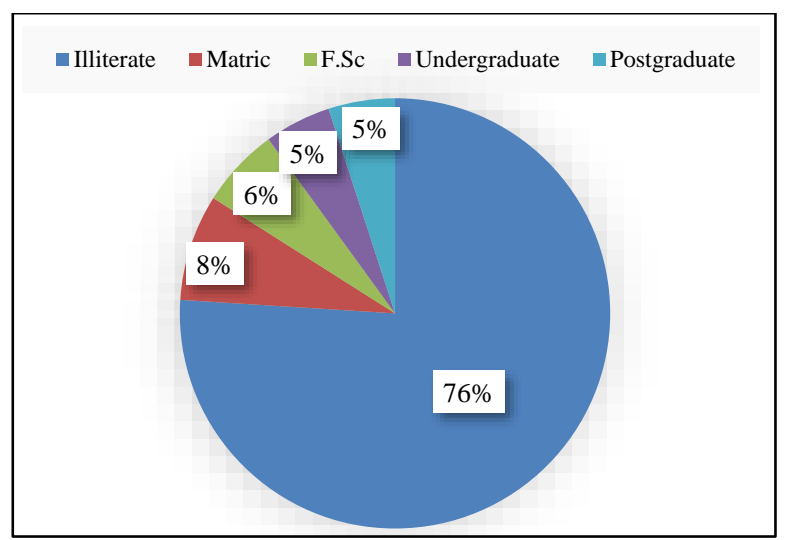

Figure 1: Educational status of participants $(n=200)$.

The result showed that the use of contraceptives did not increase as the literacy rate went up.

Table 1: Educational status and use of any type of contraceptives $(n=200)$.

\begin{tabular}{|l|c|c|c|}
\hline \multirow{2}{*}{$\begin{array}{c}\text { Educational } \\
\text { status }\end{array}$} & \multicolumn{2}{|c|}{$\begin{array}{c}\text { Do you use any type of } \\
\text { contraceptives? }\end{array}$} & \multirow{2}{*}{ Total } \\
\cline { 2 - 3 } & Yes & No & \\
\hline Illiterate & 57 & 96 & 153 \\
\hline Matric & 06 & 10 & 16 \\
\hline F.Sc. & 06 & 06 & 12 \\
\hline Undergraduate & 04 & 05 & 09 \\
\hline Postgraduate & 07 & 03 & 10 \\
\hline \multicolumn{1}{|c|}{ Total } & 80 & 120 & 200 \\
\hline
\end{tabular}

$49.5 \%$ of the women had a family size of 4 and above, $28 \%$ of women had family size of $2-3$ children while $17 \%$ of women had only one child. Contraception increased as the family size progressed and was highly statistically significant with $p=0.04$.

Table 2: Number of children and use of any type of contraceptives $(\mathbf{n}=200)$.

\begin{tabular}{|c|c|c|c|}
\hline \multirow{2}{*}{$\begin{array}{c}\text { Number of } \\
\text { children }\end{array}$} & \multicolumn{2}{|c|}{$\begin{array}{c}\text { Do you use any type of } \\
\text { contraceptives }\end{array}$} & \multirow{2}{*}{ Total } \\
\cline { 2 - 3 } & Yes & No & \\
\hline None & 04 & 07 & 11 \\
\hline 1 & 06 & 28 & 34 \\
\hline $2-3$ & 16 & 40 & 56 \\
\hline 4 and above & 54 & 45 & 99 \\
\hline Total & 80 & 120 & 200 \\
\hline
\end{tabular}

Moving to the other variables, when asked about socioeconomic status 13 participants chose not to respond, out of those who did respond it was observed in this study that $57.5 \%$ of the participants had monthly income of $20,000-40,000,31 \%$ of participant had monthly income below 20,000 and only $3 \%$ of participant had monthly income of 40,000-60,000 and the least participants belonged to 60,000 which was above $2 \%$; as such, no trend was observed among the socioeconomic classes regarding the use of contraception

Table 3: Monthly income and the use of any type of contraceptives $(\mathbf{n}=\mathbf{2 0 0})$.

\begin{tabular}{|l|c|c|c|}
\hline \multirow{2}{*}{ Monthly Income (PKR) } & \multicolumn{2}{|c|}{$\begin{array}{c}\text { Do you use any type } \\
\text { of contraceptives? }\end{array}$} & \multirow{2}{*}{ Total } \\
\cline { 2 - 3 } & Yes & No & \\
\hline Below 20,000 & 20 & 42 & 62 \\
\hline $20,000-40,000$ & 51 & 64 & 115 \\
\hline $40,000-60,000$ & 03 & 03 & 6 \\
\hline 60,000 and above & 04 & 0 & 4 \\
\hline Not applicable & 02 & 11 & 13 \\
\hline Total & 80 & 120 & 200 \\
\hline
\end{tabular}

All the women were aware of at least one family planning method. The most common source of awareness regarding family planning methods was mainly the friends and family of the women, which was $46.5 \%$. When asked about emergency contraception only $10.5 \%$ was aware of it. The side effects of oral contraceptive were known by $74.5 \%$ of women.

When asked specifically regarding which type of contraceptive method women were using the most prevalent method was oral contraceptive pills as $23 \%$ of women were using OCP and the least prevalent method was surgical methods $(1 \%)$.

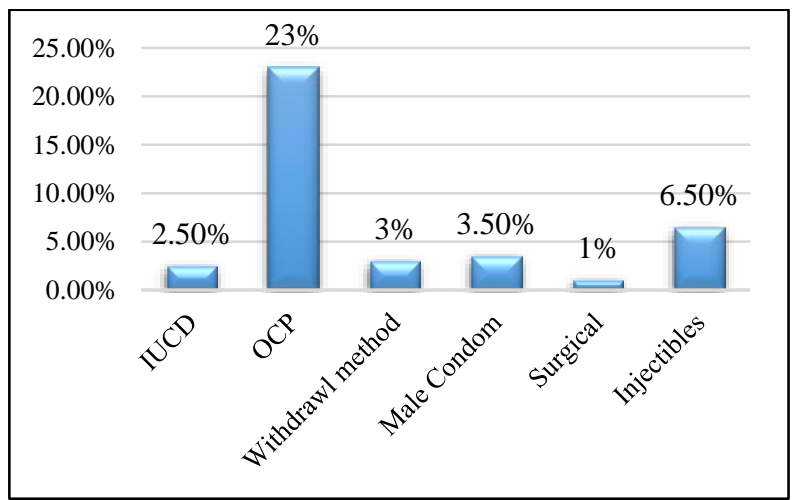

Figure 2: Prevalence of each type of contraception used

By asking the question: do you think it is necessary to have contraceptive knowledge? And do you think awareness in couples regarding contraception is important? The attitude of respondents was obtained. It was noticed that $83.25 \%$ of the respondents approve toward family planning methods means showing positive attitude.

On asking question that who should decide time and method of contraception $10.5 \%$ women said that it was the husband's decision alone to decide time and method of contraceptive use and $78.5 \%$ said it was both the husband and wife's decision. 
When the participants were interviewed, why they did not use contraception the most frequent answer was religious reasons or conservative thoughts $(30 \%)$ and $17.8 \%$ of women said that their husband did not allow them to use any method of contraception.

In the end, it was found that $38.5 \%$ of participants had undergone an unplanned pregnancy.

\section{DISCUSSION}

The surveying for this cross-sectional study covered a broad age group of $25-34$ years (31\% participants), a similar study was conducted in India to assess the knowledge attitude, attitude and perception of married women which was 20-40 years.

Family planning use was observed in $39.5 \%$ of study participants in our study. A similar study conducted in Chakwal, Mianwali and Bhakkar (Punjab) recorded the unmet needs of for contraception as $40.6 \%, 36.6 \%$ and $31.9 \%{ }^{10}$

Although Pakistan was one of the first countries in Asia to launch national family planning programs, current modern contraception use stands at $26 \% .^{10}$

In our study $24 \%$ of participants had education above primary level which is in line with a study conducted in Kohat in which $20 \%$ had education above primary level. ${ }^{11}$ This is because our study and the study in Kohat both were conducted in government hospitals in Pakistan where usually poor people seek medical treatment that are mostly uneducated. ${ }^{12}$

Women illiteracy is one of the key factors that affect their knowledge regarding different method of contraception.

Study in 2 districts of Sindh showed mean parity and number of living children as 4 and above. Our study showed similar results with $49.5 \%$ of women having family size of 4 and above showing increase in contraceptive use with increase in family size. $^{14}$

A study in Burhan village showed that $50 \%$ of household earned less than Rs. 3000 per month and $70 \%$ of these women belonged to households that earned 6000 or less which placed them below the poverty line ${ }^{13}$ where as $31 \%$ of participants in our study earned below PKR 20,000. The lower income of the families increases the desire for large families as there is inverse relation between socio-economic status and number of children.

A study conducted in Isra university hospital Hyderabad showed oral contraceptive pills was used by $13.6 \%$ of women which was little bit different from our result in which oral contraceptive pills was used by $30 \%$ of women as our study was conducted in government hospital where mostly poor people seek medical treatment so our contraceptive pills was more feasible for them. ${ }^{14}$

The source of awareness of family planning methods was mainly friends and family of the participants was $46 \%$ in our study which is similar to hospital-based study in two districts of Sindh which showed $43 \%$ of participants acquired knowledge from relatives and friends in Tando Allahyar and Jamshoro who also had a sample size of 200 women. ${ }^{15}$

In study conducted in tertiary care hospital in Pakistan $85 \%$ of women had positive attitude towards contraception, which is similar to $83.25 \%$ of positive attitude of women in our study. ${ }^{16}$

Couples joint decision making was a stronger determinant of use of contraceptive methods than women only decision making which was similar to our study in which $78.5 \%$ of women said that it was both husband and wife decision in deciding time and method of contraception. ${ }^{17}$

According to survey in Pakistan religious beliefs (28\%) was major reason for couple not using contraception which was similar to our study in which religious reasons accounted for (30\%) for non-use of contraception as women thought that children are a gift of god and use of contraceptive method was considered a $\sin .^{18}$

\section{CONCLUSION}

The results highlight the need for affordable long-term family planning services in the community. Community mobilization by efforts to help change behavior can lead to increased awareness. Desire for large family, pressure from husband and thoughts that husband should be in charge of decision-making and fear of side effects makes it difficult. There is need to improve educational status of women. Religious scholars should play their role, as religious reasons are the major cause of nonuse of contraception.

\section{REFERENCES}

1. Sathar ZA, Casterline JB. The onset of fertility transition in Pakistan. Popul Develop Rev1998; 24:773-96.

2. Population Planning Council of Pakistan. Pakistan fertility survey: first report. Islamabad: The Council; 1976.

3. National Institute of Population Studies, IRD/Macro International Inc. Pakistan demographic and health survey 19901991. Columbia: IRD / Macro International;1992.

4. National Institute of Population Studies. Pakistan fertility and family planning survey 1996-1997. Islamabad: The
Institute; 1998.

5. Hakim A, Sultan M, Ahmed F. Pakistan reproductive health and family planning survey 2001.Islamabad: The Institute 2001. p.60-2.

6. UNFPA worldwide. Population, health and socioeconomic indicators/policy developments. Overview Pakistan: key statistics 2002. Available from: http://www.unfpa.org/profile/pakistan.cf.

7. Pakistan Demographics Profile 2018, https://www.indexmundi.com/pakistan/de mographics_profile.html.

8. Khan MA. Factors affecting use of contraception in Matlab, Bangladesh. J Biosoc Sci 1996;28:265-79.

9. Pakistan Reproductive Health and Family Planning Survey 2000-2001. Islamabad: National Institute of population studies 2001:60-2.

10. Azmat SK, Ali M, Ishaque M, Mustafa G, Hameed W, Khan OF, et al. Assessing predictors of contraceptive use and demand for family planning services in underserved areas of Punjab province in Pakistan: results of a cross-sectional baseline survey. Reprod Health. 2015;12:25. 
11. Jabeen M, Fouzia Gul F, Wazir F, Javed $\mathrm{N}$. Knowledge, attitude and practices of contraception in women of reproductive age. Gomal J Med Sci 2011 JulDec;9(2):223-9.

12. Inamullah $H$, Sarwar $M$, Khan $N$, Hifazatullah, Nasiruddin M, Hussain I. Attitude of religious class toward contemporary female higher education. IBERJ- Special Edition. 2010;9:11-6.

13. Sultana A, Qizilbash AA. Factors associated with failure of family planning methods in Pakistan: Burhan village case study. (2004). Working paper series \# 91,
1-22. Published by Sustainable Development Policy Institute, Islamabad, Pakistan. www.sdpi.org.

14. Haider G, Parveen N, Rani S, Haider A. Family planning practices and its awareness among multiparous women. RMJ.2009; 34(2): 183-6.

15. Bibi S, Memon A, Memon Z, Bibi M. Contraceptive knowledge and practices in two districts of Sindh, Pakistan: A hospital based study, J Pak Med Assoc. 2008 May;58(5):254-8.

16. Khawaja N, Tayyeb R, Malik N. Awareness and practices of contraception among Pakistani women attending a tertiary care hospital. J Obstet Gynaecol. (Lahore) 2004; 24: 564-7.

17. Hameed W, Azmat SK, Ali M, Sheikh MI, Abbas G, Temmerman M, et al. Women's Empowerment and Contraceptive Use: The Role of Independent versus Couples' Decision-Making, from a Lower MiddleIncome Country Perspective. PLoS One 2014;9:e104633.

18. Sultan M, Cleland JG, Ali MM. Assessment of a new approach to family planning services in rural Pakistan. Am J Public Health 2002;92:1168-72. 